\title{
Limited mid-water scavenging of trawl discards
}

\author{
Karim Erzini*, Pedro Monteiro, Artur Araújo and Margarida Castro \\ Centro de Ciências do Mar (CGMAR), Universidade do Algarve, 8000-117 Faro, Portugal. \\ *Corresponding author, e-mail: kerzini@ualg.pt
}

\begin{abstract}
The consumption or scavenging of fish in the water column at depths from 75 to $275 \mathrm{~m}$ in Algarve (southern Portugal) trawl fishing grounds was evaluated. Longlines were used to suspend baits throughout the water column while electric fishing reels were used to simulate sinking discards. Eighteen species were caught, with higher catch rates near the surface than near the bottom. However, scavenging rates were generally highest near the bottom and lowest in the middle of the water column. At depths less than $100 \mathrm{~m}$ the majority or all the fish were scavenged throughout the water column, while at depths greater than $200 \mathrm{~m}$ most of the fish were untouched after periods of time greater than would be required for them to sink to the bottom. Since other studies have shown that most small fish discards are scavenged at the surface by sea birds and most of the discarded species that sink are either too large or not attractive to pelagic predators, these results suggest that mid-water scavenging of trawl discards in deep water is relatively unimportant.
\end{abstract}

\section{INTRODUCTION}

Most trawl fisheries are characterized by high and variable discard rates (Tingley et al., 2000). On-board sampling in the Algarve (southern Portugal) from March 1996 to June 1997 showed that on average, fish trawlers operating on the continental shelf discarded $62 \%$ of the biomass brought on board while deeper water crustacean trawlers discarded an average of $70 \%$ of the catch (Borges et al., 2001). Based on these mean discard rates Borges et al. (2001) estimated that the 37 trawlers operating in Algarve waters discarded between 9044 and 12934 tn of fish and invertebrates while landing a total of $5543 \mathrm{tn}$ in 1996. With an estimated global annual average of 27 million tn, discarding in marine commercial fisheries is generally perceived as a problem that should be eliminated or reduced (Alverson et al., 1994).

Ecosystem level effects of fishing activities, including discarding, have received considerable attention in recent years (Hall, 1999; Kaiser \& de Groot, 2000; Tingley et al., 2000). It is recognized that the contribution of discards to the energy budget may be significant in some marine ecosystems (Pauly \& Christensen, 1995; Bozzano \& Sardá, 2002). However, while the impact of discarding at the species or population level can be quantified in terms of population dynamics parameters, the effects of discarding on community structure, trophic interactions and stability are not well known.

To date, most studies have focused on quantifying discards and understanding the reasons for discarding (Tingley et al., 2000). With the exception of studies on the consumption at the surface and the importance of discards for sea birds (surface consumption) and scavenging on the bottom, there has been relatively little research on the fate of discards, particularly in mid-water. Here, we report on experiments carried out to evaluate mid-water scavenging of discards on trawl fishing grounds off the Algarve.

\section{MATERIALS AND METHODS}

Two methodologies were used to evaluate mid-water consumption in daytime: experimental fishing with vertical longlines and electric fishing reels. Three longlines with the following characteristics were constructed: approximately $500 \mathrm{~m}$ mainline of $1.6-\mathrm{mm}$ diameter monofilament, $1.2 \mathrm{~m}$ long and $0.9-\mathrm{mm}$ diameter monofilament gangions attached with a swivel to the mainline at 3.5 to $3.6 \mathrm{~m}$ intervals and MUSTAD brand size 4/0 hooks. A fourth longline differing in hook size (MUSTAD size 7) and gangion diameter $(1.1-\mathrm{mm})$ was also constructed.

The second methodology involved the use of two Krystal Fishing electric reels to simulate sinking discards. The reels were loaded with approximately $800 \mathrm{~m}$ of $80 \mathrm{lb}$ Dacron. The terminal tackle consisted of a downrigger lead weight of 3 to $6 \mathrm{~kg}$ and four hooks. Gangions were $0.9-\mathrm{mm}$ in diameter, approximately $1 \mathrm{~m}$ long and attached to 3 -way swivels spaced 1 to $1.5 \mathrm{~m}$ apart.

The longlines were baited with chub mackerel (Scomber japonicus) and sardine (Sardina pilchardus) and deployed at depths fished by trawlers. The longlines were set in the direction of the current so that they remained stretched and ensuring that the entire water column was fished. This was achieved by attaching a rock at one end as a weight and a buoy or several buoys at the other end. Preliminary experiments with 15 of the most important fish discard species showed that sinking rates varied from 3 to $10 \mathrm{~m} / \mathrm{min}$ and consequently, fish discards would take from at least $20 \mathrm{~min}$ to more than $60 \mathrm{~min}$ to reach a depth of $200 \mathrm{~m}$ (Castro et al., 1999). The longlines were fished for periods of time that were assumed to be more than the time it would take discarded species to sink to the bottom at the depths the experiments were carried out.

The entire longline fishing operation was manual. As the longlines were hauled, the states of the baits and the catches were recorded along the length of the longline. The 


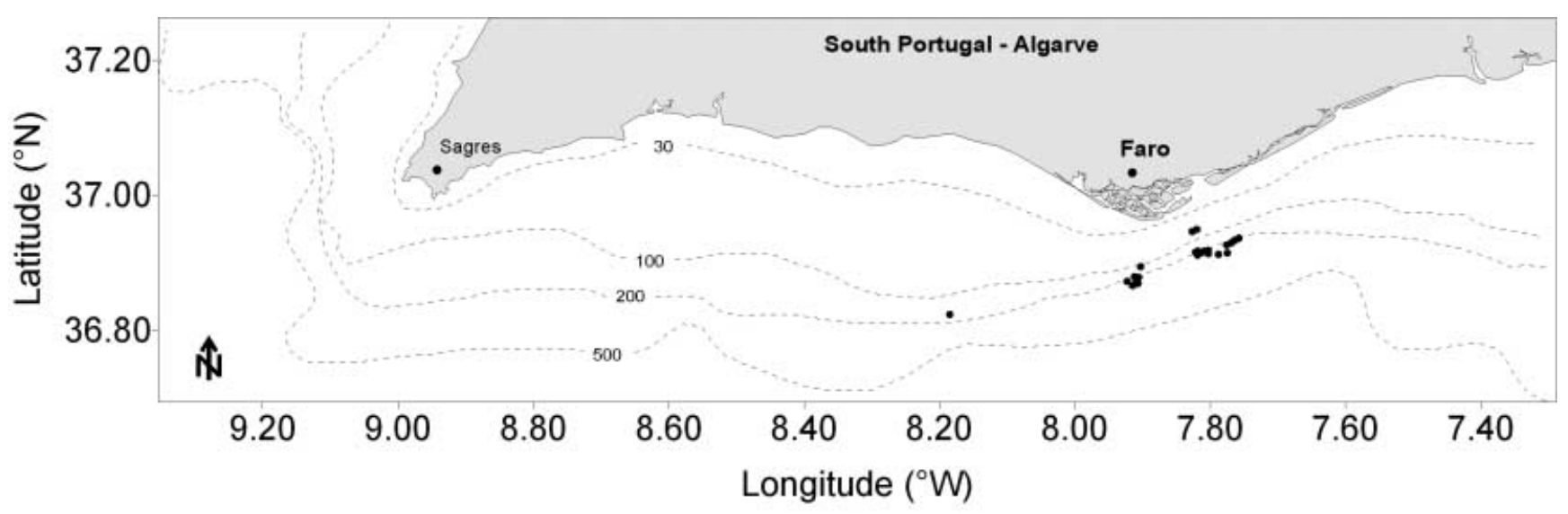

Figure 1. Map of the Algarve (southern Portugal) showing the location of the vertical longline sets.

following 4-point scale was used: 0 -bait not consumed, 1 - bait moderately consumed, 2-bait very consumed and 3-totally consumed. All fish that were caught were identified and measured, and the hook position (1 to 144 ) recorded.

To evaluate scavenging at different levels of the water column, the data were analysed by dividing each longline into three sections (top, middle and bottom) with equal numbers of hooks. Differences in scavenging were evaluated by calculating an impact factor based on the above scale for each section and for the whole longline. The impact factor was calculated as the sum of the catch, bait moderately consumed, bait very consumed and bait totally consumed categories, divided by the total number of baited hooks per set or per longline section and represents the proportion of baits that were partially or totally consumed or scavenged. Analysis of variance (ANOVA) was used to test for differences between the different longline levels, depth (less than $200 \mathrm{~m}$, greater than $200 \mathrm{~m}$ ) and their interaction. The arcsine of the square root was used to transform the consumption index data prior to ANOVA.

For the electric reel experiments, hooks were baited with sardines and then lowered to the bottom at speeds judged to be representative of sinking discards. Depths at each drop were recorded. As soon as the weights reached the bottom, the line was reeled in and the hooks inspected. As in the trials with the longlines, the state of the bait was classified. Hooks were re-baited if there was any evidence of scavenging or consumption and the experimental trials repeated continuously. Analysis of variance using the transformed impact factors was used to evaluate differences due to depth (less than $135 \mathrm{~m}$, greater than $135 \mathrm{~m})$.

\section{RESULTS}

Nine fishing trips were carried out from 25 May to 15 August 1998. A total of 28 vertical longline sets were made, of which 22 were with with the smaller $4 / 0$ hooks $(\mathrm{N}=3069)$ while six were the larger no. 7 hooks $(\mathrm{N}=842)$, resulting in a total of 3911 hooks fished overall. Soak time ranged from $56 \mathrm{~min}$ to $3 \mathrm{~h}$ and $18 \mathrm{~min}$, with a mean soak time of $2 \mathrm{~h}$ and $6 \mathrm{~min}$. The mean fishing depth was $196 \mathrm{~m}(\mathrm{SD}=50)$ with all but three sets at depths between 170 and $275 \mathrm{~m}$ (Figure 1).
Table 1. Catch by longline level for all longline sets. $A$ is the top (near surface) section, $B$ is the middle section and $C$ is the lower (near bottom) section.

\begin{tabular}{|c|c|c|c|c|}
\hline \multirow[b]{2}{*}{ Species } & \multicolumn{4}{|c|}{ Longline level } \\
\hline & A & $\mathrm{B}$ & $\mathrm{C}$ & Total \\
\hline Antedon petasus & 0 & 0 & 1 & 1 \\
\hline Boops boops & 0 & 1 & 2 & 3 \\
\hline Conger conger & 0 & 1 & 4 & 5 \\
\hline Coryphaena equiselis & 3 & 0 & 0 & 3 \\
\hline Dasyatis pastinaca & 1 & 0 & 0 & 1 \\
\hline Gymnura altavela & 0 & 0 & 1 & 1 \\
\hline Helicolenus dactylopterus & 0 & 0 & 1 & 1 \\
\hline Isurus oxyrinchus & 0 & 0 & 1 & 1 \\
\hline Lagocephalus lagocephalus & 2 & 0 & 0 & 2 \\
\hline Merluccius merluccius & 0 & 1 & 4 & 5 \\
\hline Mola mola & 0 & 0 & 1 & 1 \\
\hline Portunidae & 5 & 3 & 0 & 8 \\
\hline Prionace glauca & 4 & 0 & 0 & 4 \\
\hline Scomber japonicus & 34 & 27 & 9 & 70 \\
\hline Scomber scombrus & 2 & 1 & 0 & 3 \\
\hline Serranus hepatus & 0 & 0 & 1 & 1 \\
\hline Trachurus picturatus & 0 & 1 & 1 & 2 \\
\hline Trachurus trachurus & 0 & 1 & 0 & 1 \\
\hline Total & 51 & 36 & 26 & 113 \\
\hline Number of species & 7 & 8 & 11 & \\
\hline
\end{tabular}

The overall catch distribution by section of longline is given in Table 1 . The vertical longlines caught a total of 113 fish and crustaceans, with the nos. $4 / 0$ and 7 hooks accounting for 103 and 10 respectively, for an overall catch rate of 2.89 fish per 100 hooks. As can be seen in Table 1, the fish caught ranged from pelagic sharks (blue shark, Prionace glauca; mako shark, Isurus oxyrinchus) and fish (e.g. dolphin fish, Coryphaena equiselis) to demersal species such as conger eel (Conger conger). The dominant species in numbers was the chub mackerel (Scomberjaponicus) with 70 fish (61\%).

Catches were highest in the upper, near surface section (A) of the longline (45\%), decreasing to $32 \%$ and $23 \%$ in the middle (B) and bottom $(\mathrm{C})$ sections respectively. The mean catch per longline set is given in Figure 2A. The 

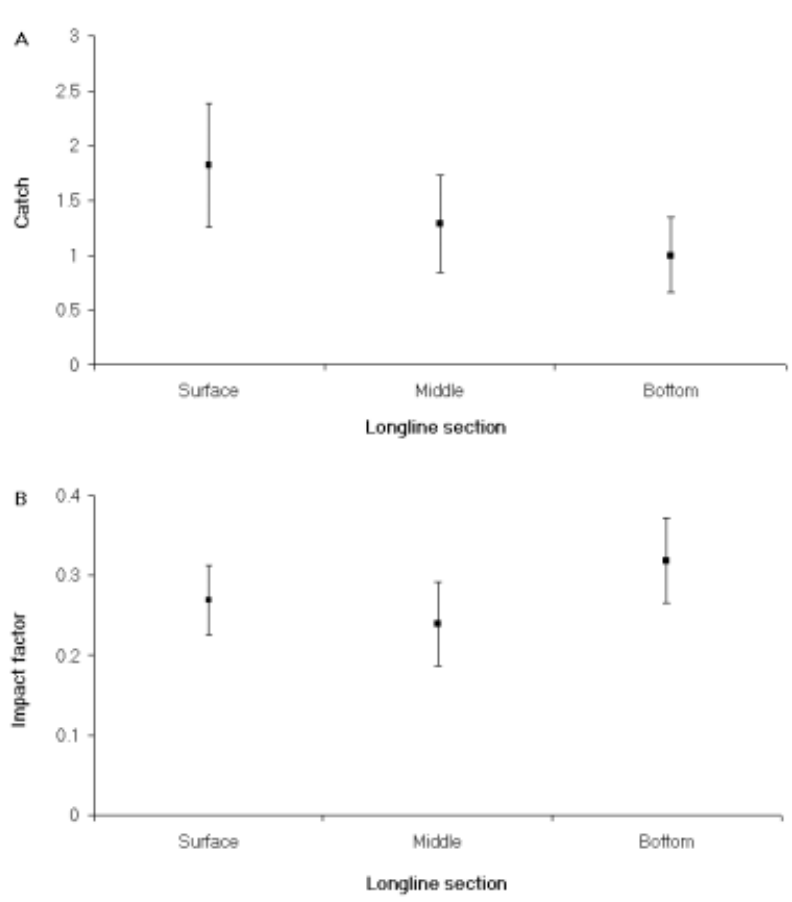

Figure 2. Mean $( \pm \mathrm{SE})$ catch $(\mathrm{A})$ and scavenging rates $( \pm \mathrm{SE})(\mathrm{B})$ at different levels of the water column (surface, middle, bottom).

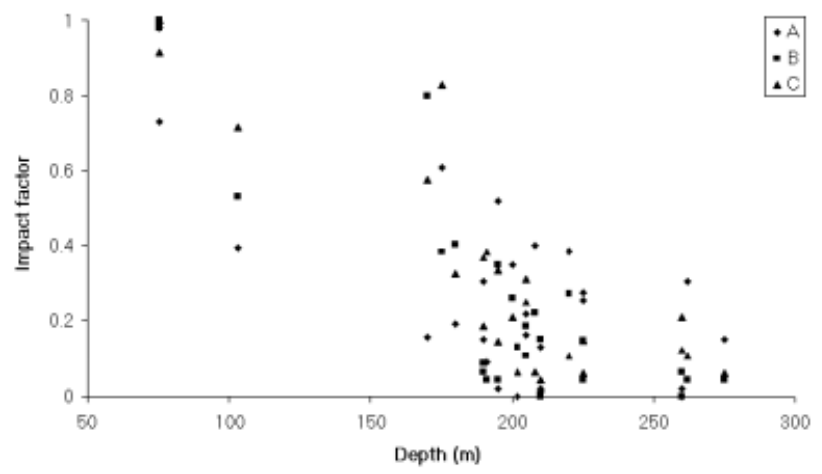

Figure 3. Relationships between scavenging rates (impact factor) and depth for different levels of the water column (longline sections: A, surface; B, middle; C, bottom).

number of species increased from the surface to the bottom (Table 1).

Overall, $73 \%$ of the hooks were retrieved still baited and with no signs of consumption or scavenging. For the no. $4 / 0$ hooks $30 \%$ of the baits were partially or totally consumed, compared with only $18 \%$ for the no. 7 hooks. Figure 2B shows the mean impact factors per longline set and section. Consumption or scavenging of bait was lowest in the middle section and highest in the bottom section of the longline. However, analysis of variance results indicate no difference in the means of the transformed (arcsine of the square root) data $(P>0.05)$.

The relationship between soak time and the proportion of baits that were consumed or scavenged was not significant $\left(P>0.05, \mathrm{R}^{2}=0.0008\right)$. However, depth was an important factor for consumption in all three longline levels. Two way ANOVA showed that depth was highly significant $(P<0.05)$ while longline level and the interaction of longline level and depth were not significant $(P>0.05)$. As can be seen in Figure 3, at the very shallowest depths $(<100 \mathrm{~m})$, all the baits were partly or totally consumed (impact factor $=1.0$ ), while at depths greater than $250 \mathrm{~m}$ the majority of the hooks were retrieved with untouched baits.

A total of 136 drops with two electric reels were carried out between May and December 1998 in the same area where the vertical longline trials took place (Figure 1). Each drop consisted of four baited hooks, resulting in a total of 544 baits tested for consumption in the water column. Depths ranged from 99 to $258 \mathrm{~m}$, with a mean depth of $148 \mathrm{~m}(\mathrm{SD}=44 \mathrm{~m})$.

No fish were caught in the experimental fishing with the electric reels. However, some of the baits were partially or totally consumed. Approximately $85 \%$ of the baits were retrieved untouched by predators or scavengers, while $10 \%$ of the baits disappeared, presumably due to consumption in the water column, and $5 \%$ showed signs of consumption. The impact factors for fishing trials at different depths did not differ significantly $(P>0.05)$. For 296 hooks fished at depths $<135 \mathrm{~m}$, the mean impact factor (arcsine transformed) was $0.276(\mathrm{SD}=0.397)$ while for depths greater than $135 \mathrm{~m}$ and 248 baits the mean was $0.275(\mathrm{SD}=0.320)$.

\section{DISCUSSION}

The few studies on mid-water consumption of discards were based either on analysis of stomach contents of fish or as in our study on experiments with baits suspended in the water column. Laptikhovsky \& Fetisov (1999) studied the stomach contents of six fish species from squid (Illex argentinus) trawling grounds on the Patagonian shelf and slope at depths from 105 to $710 \mathrm{~m}$ and found that discarded squid remains represented 20 to $40 \%$ of the diet of common hake (Merluccius hubbsi), southern cod (Notothenia ramsayi) and grenadier (Macrourus holotrachys). The stomach contents of 40 fish species from trawling grounds at depths of 138 to $444 \mathrm{~m}$ were studied by Yamamura (1997). Three of the species, Pacific cod (Gadus macrocephalus), walleye pollock (Theragra chalcogramma) and oilfish (Ruvettus pretiosus) contained Pacific saury (Colblabis saira), a pelagic fish found only in the surface layer and discarded in considerable quantities by the Japanese dip net fishermen. Yamamura (1997) estimated that discarded saury made up $21.8 \%$ of the total diet of the deep stratum (153 to $444 \mathrm{~m}$ ) fish assemblage during the fishing season. While it is not known in either of these two studies where in the water column the discards were consumed, hake, walleye pollock and oilfish generally feed off the bottom, unlike the southern cod, the grenadier and the Pacific cod (Froese \& Pauly, 1999).

Hill \& Wassenberg (1990) suspended baits in midwater on a $18 \mathrm{~m}$ line for $10 \mathrm{~min}$ immediately after hauling of the trawl net in an area between Australia and Papua New Guinea. They reported that $80 \%$ of the baits were retrieved intact and scavenging rates were higher during the night. Since most of the baits were removed completely, they concluded that large scavengers such as sharks and dolphins were responsible. Similar experiments with vertical set lines in Moreton Bay resulted in the consumption of only two out of 185 baits from 23 sets (Wassenberg \& Hill, 1990). No mid-water scavenging of prawn trawling discards was observed near the Great Barrier Reef (Hill \& 
Wassenberg, 2000). These studies were carried out in relatively shallow fishing grounds at depths of less than $50 \mathrm{~m}$. Given the sinking rates of discards, Hill \& Wassenberg (2000) concluded that discards did not remain in the water column long enough for significant scavenging to take place.

The results of our study suggest that scavenging does take place throughout the water column, but at variable rates. Scavenging was generally much more significant on the continental shelf at depths less than $100 \mathrm{~m}$, compared to depths greater than $200 \mathrm{~m}$ on the upper continental slope. Relatively high rates of consumption of suspended baits did occur in some of the vertical longline sets in which considerable numbers of mackerel were caught in adjacent hooks, suggesting that a school of the fish had encountered the longline. However, the generally low catch rates and the high proportion of intact baits after periods of time that were greater than necessary for discards to reach the bottom indicates that water column scavengers were relatively rare and/or patchily distributed in the study area.

We used sardines and chub mackerel in the vertical longline and electric reel fishing trials. Both species are regularly discarded in Algarve waters. Borges et al. (2000) reported that in 51 trawl hauls from 1997 to 1998, chub mackerel was the most important discard species with about $9000 \mathrm{~kg}$ while the sardine was the sixth with more than $1000 \mathrm{~kg}$ discarded. Unlike many of the 140 fish species discarded by trawlers (Borges et al., 2000), sardines and chub mackerel are prey species that are attractive to a wide variety of predators. Other discard species such as small sharks, rays and skates that make up an important part of trawl discards (Monteiro et al., 2001) are less likely to be scavenged as they sink through the water column (Hill \& Wassenberg, 1990). Since most of the smaller and more easily consumed fish discards are scavenged by sea birds at the surface (Castro et al., 1999), we conclude that mid-water scavenging may be even less significant overall than the estimates based on sardines and chub mackerel obtained in our experiments.

We would like to thank Mestres António da Branca and Helder Ferreira for the use of their vessels and for their help with the longlines and the electric reels. Thanks are also due to two anonymous referees whose comments helped improve the manuscript. This work was funded in part by the European Commission, Directorate General Fisheries (Studies Project no. 96-063).

\section{REFERENCES}

Alverson, D.L., Freeberg, M.H., Murawski, S.A. \& Pope, J.G., 1994. A global assessment of fisheries bycatch and discards. FAO Fisheries Technical Paper, 339, 1-233.

Borges, T.C., Bentes, L., Cristo, M., Costa, M.E., Erzini, K., Olim, S. \& Pais, C., 2000. Analysis of fisheries discards from the south coast of Portugal (DISCALG). Final Report to the European Commission, Directorate General Fisheries, no. 97/087, 207 pp.

Borges, T.C., Erzini, K., Bentes, L., Costa, M.E., Gonçalves, J.M.S., Lino, P.G., Pais, C. \& Ribeiro, J., 2001. By-catch and discarding practices in five Algarve (southern Portugal) métiers. Fournal of Applied Ichthyology, 17, 104-114.

Bozzano, A. \& Sardá, F., 2002. Fishery discard consumption rate and scavenging activity in the northwestern Mediterranean Sea. ICES Journal of Marine Science, 59, 15-28.

Castro, M. et al., 1999. Methodologies to study the impact of discards in trawl fisheries. Final Report to the European Commission, Directorate General Fisheries, Project no. 96-063.

Froese, R. \& Pauly, D., ed., 1999. Fishbase 99. WorldWide Web electronic publication. www.fishbase.org, September 2002.

Hall, S.J., 1999. The effects of fishing on marine ecosystems and communities. Oxford: Blackwell Science Ltd.

Hill, B.J. \& Wassenberg, T.J., 1990. Fate of discards from prawn trawlers in Torres Strait. Australian Fournal of Marine and Freshwater Research, 41, 53-64.

Hill, B.J. \& Wassenberg, T.J., 2000. The probable fate of discards from trawlers fishing near coral reefs. A study in the northern Great Barrier Reef, Australia. Fisheries Research, 48, 277-286.

Kaiser, M.J. \& Groot, S.J. de, 2000. Effects of fishing on non-target species and habitats. Biological, conservation and socio-economic issues. Oxford: Blackwell Science Ltd.

Lapitikhovsky, V. \& Fetisov, A., 1999. Scavenging by fish of discards from the Patagonian squid fishery. Fisheries Research, 41, 93-97.

Monteiro, P., Araújo, A., Erzini, K. \& Castro, M., 2001. Discards of the Algarve (southern Portugal) crustacean trawl fishery. Hydrobiologia, 449, 267-277.

Pauly, D. \& Christensen, V., 1995. Primary production required to sustain global fisheries. Nature, London, 374, 255-257.

Tingley, D., Erzini, K. \& Goulding, I., 2000. Evaluation of the state of knowledge concerning discard practices in European fisheries. Final Report to the European Commission, Directorate General of Fisheries, 76 pp.

Wassenberg, T.J. \& Hill, B.J., 1990. Partitioning of material discarded from prawn trawlers in Moreton Bay. Australian Fournal of Marine and Freshwater Research, 41, 27-36.

Yamamura, O., 1997. Scavenging on discarded saury by demersal fishes off Sendai Bay, northern Japan. Journal of Fish Biology, 50, 919-925.

Submitted 12 November 2002. Accepted 14 May 2003. 